\title{
Cardiovascular Oncology: Exploring the Effects of Immune Checkpoint Inhibitors on Experimental Atherosclerosis
}

K. Poels ${ }^{1}$, T.T.P. Seijkens ${ }^{1}$, P.J.H. Kusters ${ }^{1}$, M.E. Reiche1, S.M. Den Toom ${ }^{1}$, L. Beckers ${ }^{1}$, M.P.J. de Winther ${ }^{1}$, E. Lutgens ${ }^{1}$ k.poels@amc.uva.nl 1. Department of Medical Biochemistry, Amsterdam UMC - location AMC, Amsterdam, the Netherlands

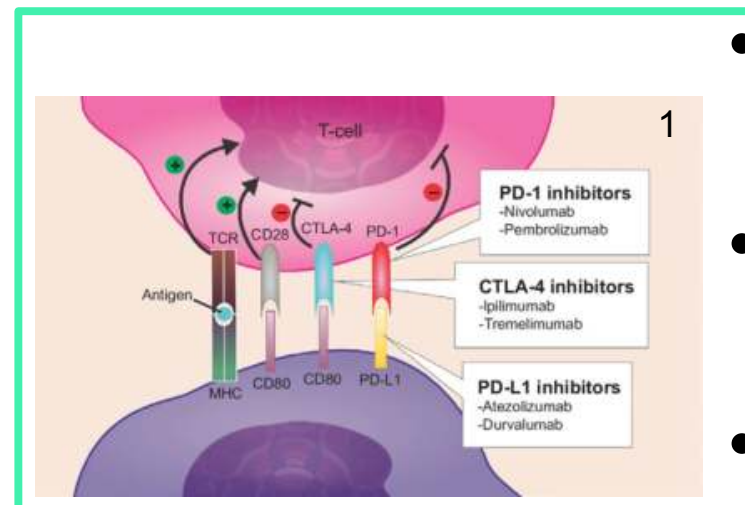

- Immune checkpoint inhibitors $(\mathrm{ICl})$ are antibodies against the co-inhibitory molecules CTLA-4, PD-1 and PD-L1 that have revolutionized cancer treatment, however cardiotoxicity of these agents is a rising problem ${ }^{3}$;

$\mathrm{ICl}$ release the natural brake on $\mathrm{T}$ cell activation, thereby enhancing antitumor $\mathrm{T}$ cell responses, but also triggering immune related adverse events, such as myocarditis ${ }^{4}$ and aggravate chronic inflammatory diseases ${ }^{5}$;

- Atherosclerosis is a lipid-driven chronic inflammatory disease of the large arteries and the underlying cause of the majority of cardiovascular diseases ${ }^{6}$.

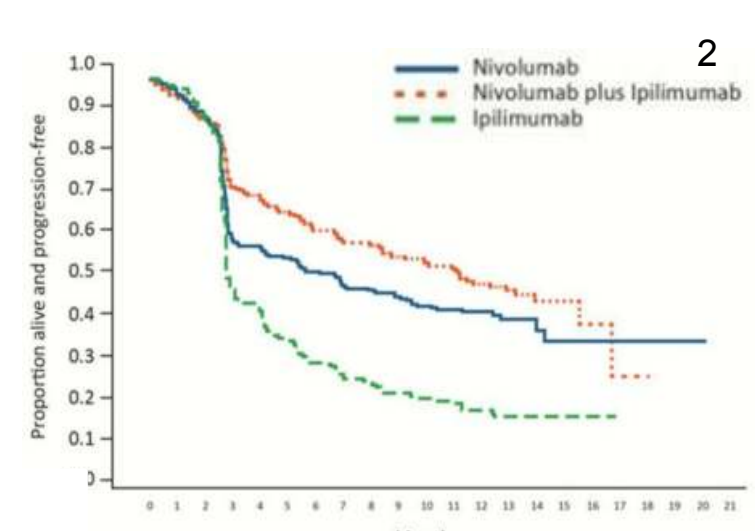

Goal: study the effect of combined aCTLA4 and aPD1 antibodies on experimental atherosclerosis

\begin{tabular}{|c|c|c|c|c|}
\hline & & veeks & \multicolumn{2}{|c|}{5 weeks } \\
\hline $\begin{array}{l}\text { 6-8 week old } \\
\text { Male } L D L r^{-1-} \text { mice }\end{array}$ & Start HCD & $\begin{array}{l}\text { Start } \\
\alpha \mathrm{CTL}\end{array}$ & & Sacrifice \\
\hline
\end{tabular}

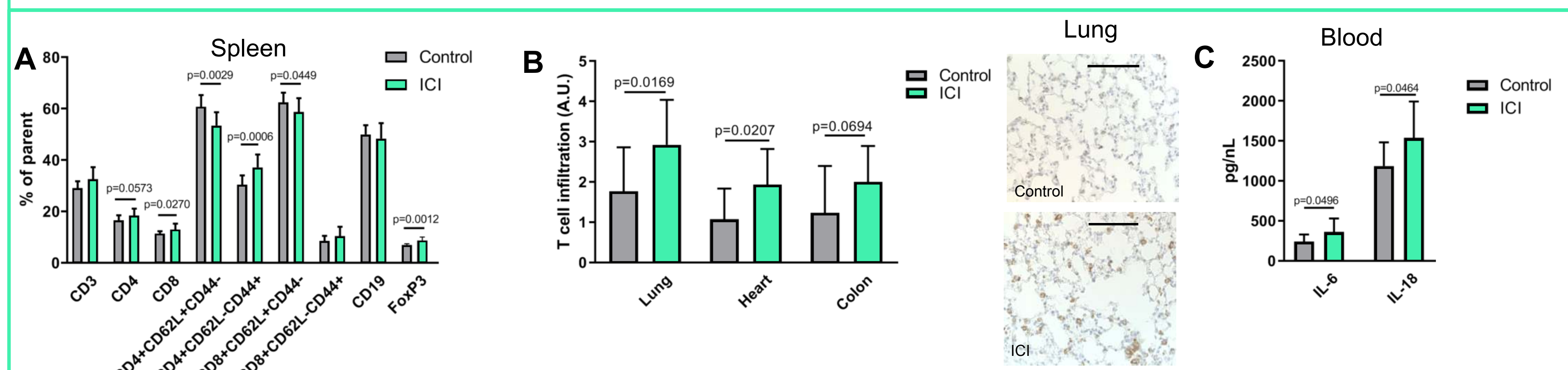

Figure 1: ICl trigger an activated T cell profile, which accumulate in organs. Systemic inflammation was evident in ICI mice.
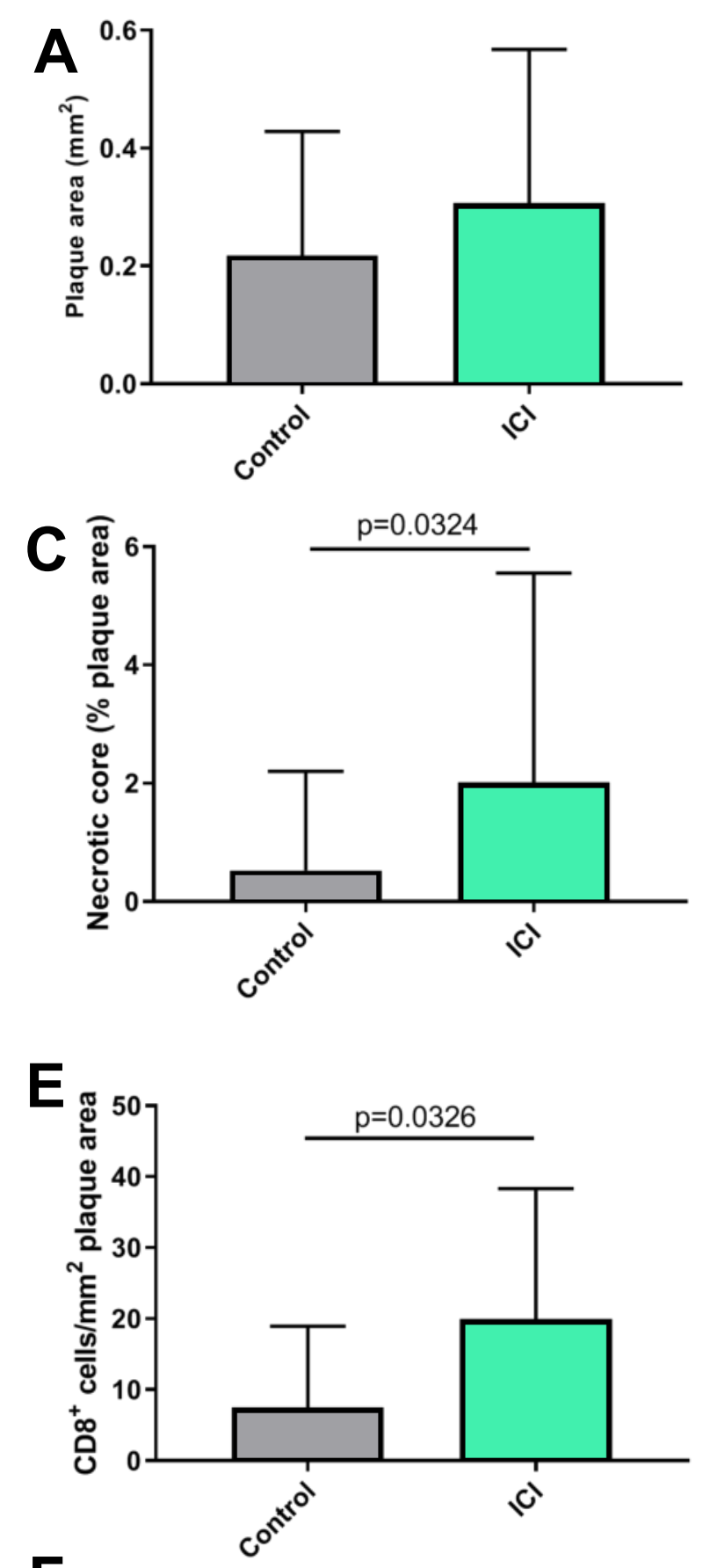

$$
\text { Fis }
$$

